\title{
SISTEM PENGELOLAAN ALUMNI PROGRAM DIII MIK UNIVERSITAS EKASAKTI
}

\section{THE MANAGEMENT SYSTEM OF ALUMNI DEPARTEMENT INFORMATIC AND COMPUTER MANAGEMENT EKASAKTI UNIVERSITY}

\author{
Danyl Mallisza \\ DIII Manajemen Informatika dan Komputer \\ Universitas Ekasakti \\ E-mail : danylmallisza2483@gmail.com
}

\begin{abstract}
Alumni have an important role for an educational institution. Alumni involvement with an institution after graduation is an important factor affecting alumni support of their almamater. But these day there is no place that can facilitate the alumni effectively. Based on that case, there is a need to develop a system that can handle it. This system can display alumnis data and job, make a topic and leave a comment on forum discussion. This system is expected to facilitate the alumnis data management process and the final project in Computer and Information System of Universitas Ekasakti. Information system of alumnis portal for Computer and Information System of Universitas Universitas Ekasakti is web based and was developed using PHP, framework CodeIgniter and MySQL database. Information system design refers to the needs of the information required by the user, and modeled into diagrams contained in the method of UML (Unified Modeling Language). With this system, we can make a website that can accommodate all the information about alumni and jobs centrally with fast, precise, and accurate.The purpose of this research is to improve alumniss data management process and the final project more effective and efficient.
\end{abstract}

Keywords: Information System, Online, UML (Unified Modeling Language).

\begin{abstract}
Abstrak
Alumni memiliki peranan yang penting untuk pengembangan sebuah institusi pendidikan. Karena alumni bisa berperan sebagai duta yang mencerminkan kualitas sebuah institusi pendidikan di ranah publik. Tetapi untuk saat ini masih belum ada wadah yang efektif yang bisa memfasilitasi alumni. Berdasarkan permasalahan tersebut, perlu dibangun sistem yang mampu menangani proses pengelolaan alumni. Sistem ini mampu menampilkan data alumni, lowongan pekerjaan, menampilkan data pekerjaan alumni, membuat topik dan mengomentari topik. Sistem ini diharapkan dapat mempermudah manajemen pengelolaan alumni pada program Diploma III Manajemen Informatika dan Komputer Universitas Ekasakti. Sistem Informasi Portal Alumni Program Diploma III Manajemen Informatika dan Komputer Universitas Ekasakti ini berbasis web dengan bahasa pemrograman PHP, framework CodeIgniter, dan basis data MySQL. Perancangan sistem informasi mengacu kepada kebutuhan-kebutuhan informasi yang diperlukan oleh pengguna, dan dimodelkan ke dalam diagram-diagram yang terdapat di dalam metode UML (Unified Modeling Language). Dengan adanya sistem ini, dapat dibuat sebuah website yang dapat menampung seluruh informasi mengenai alumni dan lowongan pekerjaan secara terpusat dengan cepat, tepat, dan
\end{abstract}


akurat. Hasil keluaran yang diharapkan dari penelitian ini adalah proses manajemen data alumni dan tugas akhir mahasiswa menjadi lebih efektif dan efisien.

Kata kunci: sistem informasi, online, UML (Unified Modeling Language).

\section{PENDAHULUAN}

Alumni memiliki peranan yang penting untuk pengembangan sebuah institusi pendidikan, karena alumni bisa berperan sebagai duta yang mencerminkan kualitas sebuah institusi pendidikan di ranah publik. Saat ini masih belum ada wadah yang efektif yang bisa memfasilitasi alumni. Berdasarkan permasalahan tersebut, perlu dibangun sistem yang mampu menangani proses pengelolaan alumni.

Data alumni merupakan salah satu contoh dari suatu sistem informasi yang dirancang untuk dapat membantu pekerjaan dari suatu instansi atau perusahan baik dalam mengolah data sampai memberikan data secara lengkap lewat tersedianya layanan informasi secara online. Sejauh ini belum ada penerapan sistem informasi pengolahan data alumni secara online pada Program Diploma III Manajemen Informatika dan Komputer Universitas Ekasakti Padang yang tentunya dapat membantu pekerjaan lebih mudah dalam mengolah, memberikan dan menampilkan data.

Program Diploma III Manajemen Informatika dan Komputer Universitas Ekasakti Padang merupakan salah satu lembaga pendidikan yang memiliki kewajiban menyediakan media komunikasi untuk memperkenalkan dan mempererat tali silahturahmi antara mahasiswa dengan para lulusannya (alumni), oleh karena itu perancangan situs web alumni perguruan tinggi ini diharapakan dapat menjadi media informasi bagi alumni maupun pihak perguruan tinggi. Sehingga tetap terjalin hubungan timbal balik antara para alumni dengan pihak kampus. Untuk memenuhi suatu kebutuhan mengenai informasi data alumni ataupun informasi Program Diploma III Manajemen Informatika dan Komputer maka dibutuhkan suatu pembangunan aplikasi yang dapat mendukung semua informasi yang dihasilkan.

Pembuatan sebuah situs web tidak bisa terlepas dengan bahasa pemrograman, dalam hal ini penulis menggunakan PHP sebagai bahasa scrip (script language) dan MySQL sebagai database server. PHP dan MySQL adalah pasangan bahasa scripting dan database server yang banyak diminati akhir-akhir ini. Ketangguhan, jaminan keamanan yang tinggi, dan kemudahan mempelajari membuat keduanya banyak dipilih untuk digunakan.

Berdasarkan entitas dan propertiesnya, sistem informasi akademik merujuk pada seperangkat sistem dan aktivitas yang digunakan untuk menata, memproses, dan menggunakan informasi sebagai sumber dalam organisasi (Sprange dan Carlson, 1982). Adapun keluaran berupa informasi yang dihasilkan oleh sistem ini akan mensuplai 
informasi kepada para pimpinan atau pembuat keputusan yang dapat diklasifikasikan pemanfaatan dan maksud yang berbeda-beda (Levin, Kirkpatrick, Rubin, 1982) seperti di bawah ini: (a) Sistem informasi akademik untuk menghasilkan laporan di berbagai bidang kegiatan seperti akademik, keuangan, personel, distribusi mahasiswa di berbagai jurusan, dan lain-lain; (b) Sistem informasi akademik untuk menjawab pertanyaan "what if'. Sistem informasi ini memanfaatkan informasi tersimpan yang perlu untuk mempertimbangkan konsekuensi tindakan; dan (c) Sistem informasi akademik untuk mendukung pengambilan keputusan, evaluasi, dan pengembangan sistem. Sistem ini mensuplai informasi untuk semua jenjang organisasi perguruan tinggi. Dalam kenyataannya, sistem informasi akademik sering ditafsirkan salah. Kesalahan tafsir ini berpangkal pada dua hal; pertama, sistem informasi sering diartikan hanya sebagai komputerisasi pekerjaan ketatausahaan; dan kedua, sistem informasi diartikan hanya sebagai "an all knowing computer which will provide answer and decision for complex problems when a manager simpley presses a few buttons" (Murdick dan Ross, 1982).

Secara spesifiki, sistem informasi akademik memiliki beberapa karakter yang cukup luas, yaitu: (a) Sistem informasi akademik bermakna sebagai pendekatanpendekatan dalam melakukan proses manajemen; (b) Komputer hanya merupakan komponen, atau alat bukan fokus sentral dari sistem informasi akademik; (c) Pimpinan berperan aktif dalam rangka sistem sebagai pengguna informasi bukan sebagai tenaga teknis ataupun operator komputer; dan (d) Esensi sistem informasi administrasi terletak pada sistem terpadu dan sistem terencana, bukan hanya urusan mekanisme pengolahan data. Sebagian besar keputusan manajemen yang ada dalam penyelenggaraan perguruan tinggi, sebagai mana lembaga-lembaga profit lainnya, bersifat berulang dan rutin.

Menurut sebuah survei (Murdick dkk. 1995) menyebutkan bahwa sekitar 90\% dari keputusan manajemen merupakan keputusan rutin. Jika mengacu pada survei di atas, maka sudah saatnya perguruan tinggi memiliki kebutuhan mendesak mengotomasi atau memprogram-kan keputusan-keputusan itu. Dengan bisa diprogramkannya keputusankeputusan manajerial di perguruan tinggi, maka para pimpinan di setiap unit bisa mencurahkan pekerjaan mereka kepada pekerjaan-pekerjaan yang sebenarnya yaitu mengambil keputusan-keputusan jangka panjang dan mencari upaya peningkatan mutu layanan lembaga jangka panjang.

Sistem ini dibagi ke dalam beberapa subsistem: (a) Seleksi dan registrasi mahasiswa baru; (b) Kurikulum dan bidang studi; (c) Perkuliahan, tugas, ujian; (d) Pengelolaan dan pengembangan dosen; dan (e) Kelulusan, wisuda, alumni Penggunaan TIK dalam mendukung proses ini merupakan salah satu bentuk kepekaan lembaga dalam mencapai kesuksesan. Terkait dengan kepekaan ini, Webb dan Pettigrew (Hoyt, 2007: 1) menyatakan bahwa kepekaan lembaga (organizational responsiveness) merupakan isu utama yang menentukan kesuksesan dalam berusaha. Selain itu, Kuratko et. Al (2001: 44) dan Liao et. Al. (2003) juga menyatakan bahwa kemampuan lembaga 
dalam menjawab perubahan lingkungan dunia luarnya merupakan faktor utama yang menentukan kinerja lembaga.

\section{METODE PENELITIAN}

Metodologi adalah kesatuan metoda, prosedur, konsep pekerjaan, aturan, yang digunakan oleh suatu ilmu pengetahuan, seni atau disiplin lainnya. Metode adalah suatu cara, teknik yang sistematik untuk mengerjakan sesuatu. Metodologi ini menekankan pada pemecahan dari sistem ke dalam subsistem yang lebih kecil, sehingga akan lebih mudah untuk dipahami, dirancang dan ditetapkan.

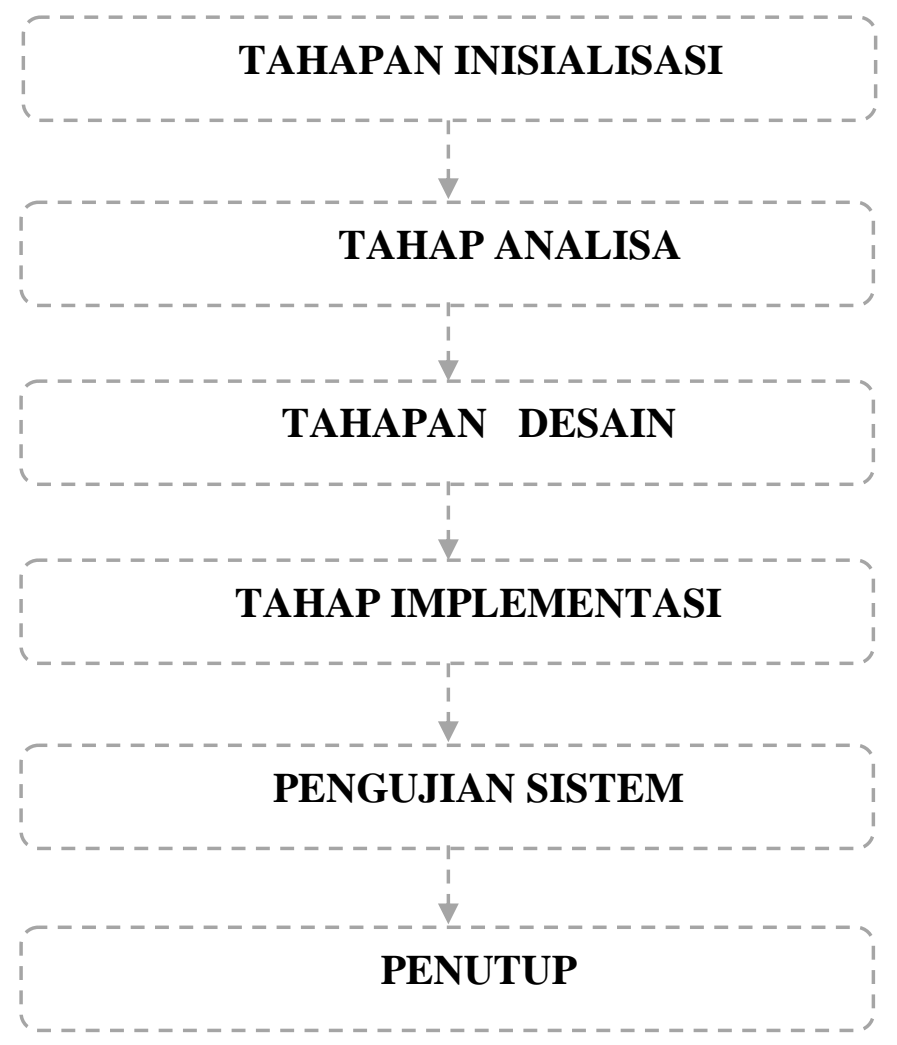

Gambar 1. Kerangka Alur Metodologi Penelitian

\section{Uraian Kerangka Kerja}

Metodologi penelitian ini dilakukan dengan cara sistematik yang digunakan sebagai pedoman peneliti dalam melaksanakan penelitian ini agar hasil yang dicapai tidak menyimpang dari tujuan yang telah ditentukan sebelumnya.Berdasarkan kerangka alur metodologi penelitian pada gambar maka masing-masing langkah dapat diuraikan sebagai berikut : 


\section{Tahapan Inisialisasi}

Untuk suatu proyek,untuk menggambarkan lingkup bisnis awal,jadwal,dan anggaran. pada tahap ini juga ditentukan tujuan dari penelitian yang kita akan lakukan yaitu :

1. Dapat mengetahui seluk-beluk sistem yang akan dirancang

2. Dapat mengetahui bahwa dengan membangun sebuah sistem pengelolaan alumni yang online dapat memperluas jaringan komunikasi serta membantu para lulusan didalam mencari pekerjaan.

3. Dapat mengetahui interaksi antara alumni serta pengelolaan data yang lebih efektif dan akurat.

\section{Tahap Analisa}

Pada metode ini analisis dilakukan dengan cara membandingkan teori dan praktek, sehingga diperoleh gambaran yang jelas tentang persamaan dan perbedaan di antara keduanya.

Setelah data-data dikumpulkan maka selanjutnya adalah melakukan analisa masalah yaitu bagaimana membangun sistem informasi pengelolaan alumni berdasarkan variabel-variabel yang ditentukan.

informasi yang mendukung dalam pengembangan perangkat lunak. Dari hasil analisis sistem diharapkan mampu menghasilkan output yang mendukung dalam pengambilan keputusan. Untuk mempermudah penggambaran akan dirancang menggunakan pemodelan sistem dengan Unified Modeling Language (UML).

3. Tahap Perancangan Sistem

Perancangan Sistem untuk membangun aplikasi e-commerce berbasis Webbase secara keseluruhan. Pada tahap ini dimulai dari perancangan database, perancangan user interface dan perancangan arsitektur perangkat lunak maupun keras. Perancangan menggunakan Unified Modeling Language (UML) serta dilanjutkan dengan mendesain prototype PHP dan MySQL untuk Webbase dan Javascript serta Adobe Photoshop CS3 dan Dreamweaver untuk desain konten.

4. Tahap Implementasi

implementasi sistem berdasarkan hasil perancangan yang telah dibuat. prototype sistem pengelolaan alumni berbasis webbase ini dirancang dan di implimentasikan pada sistem pengelolaan alumni program D III Mik Universitas Ekasakti. 


\section{Tahap pengujian.}

Pengujian prototype secara fungsionalitas ditujukan untuk dapat melakukan berbagai perbaikan dari kelemahan-kelemahan prototype dan melihat dari hasil tahapan implementasi sistem serta melihat kebenaran/kehandalan dari sistem yang dirancang.

\section{Analisis dan Perancangan Sistem}

Analisis terhadap sumber data dilakukan untuk mengetahui informasi yang harus disediakan oleh sistem, fungsi-fungsi yang dapat ditangani seperti: (1) melihat profil alumni, (2) jumlah, (3) pendokumentasian, (4) profil perkuliahan dan sebagainya. Pada dasarnya kegiatan yang dilakukan pada tahap analisis ini ada dua bagian, yaitu tahap survei pengumpulan data dan analisis terstruktur yang secara garis besar untuk memperoleh pengertian dari permasalahan-permasalahan, efisiensi dan pertimbanganpertimbangan yang mengarah ke pengembangan sistem.

Memperkirakan kendala-kendala yang akan dihadapi dalam pengembangan sistem tersebut dan menentukan solusi-solusi alternatif pendahuluan. Analisa dan Perancangan bertujuan untuk membentuk optimasi dari aplikasi yang akan kita bangun dengan mempertimbangkan faktor-faktor permasalahan kebutuhan yang ada dalam sistem. Upaya yang dapat dilakukan adalah dengan mencari kombinasi perangkat lunak dan teknologi yang tepat sehingga dapat menghasilkan hasil yang tepat dan mudah diimplementasikan.

Sistem ini dirancang menggunakan alat bantu berupa UML (Unified Modelling Language) agar mempermudah memindahkan konsep sistem yang dirancang ke dalam bentuk program, dimana perancangannya digambarkan dalam bentuk diagram-diagram berikut : 


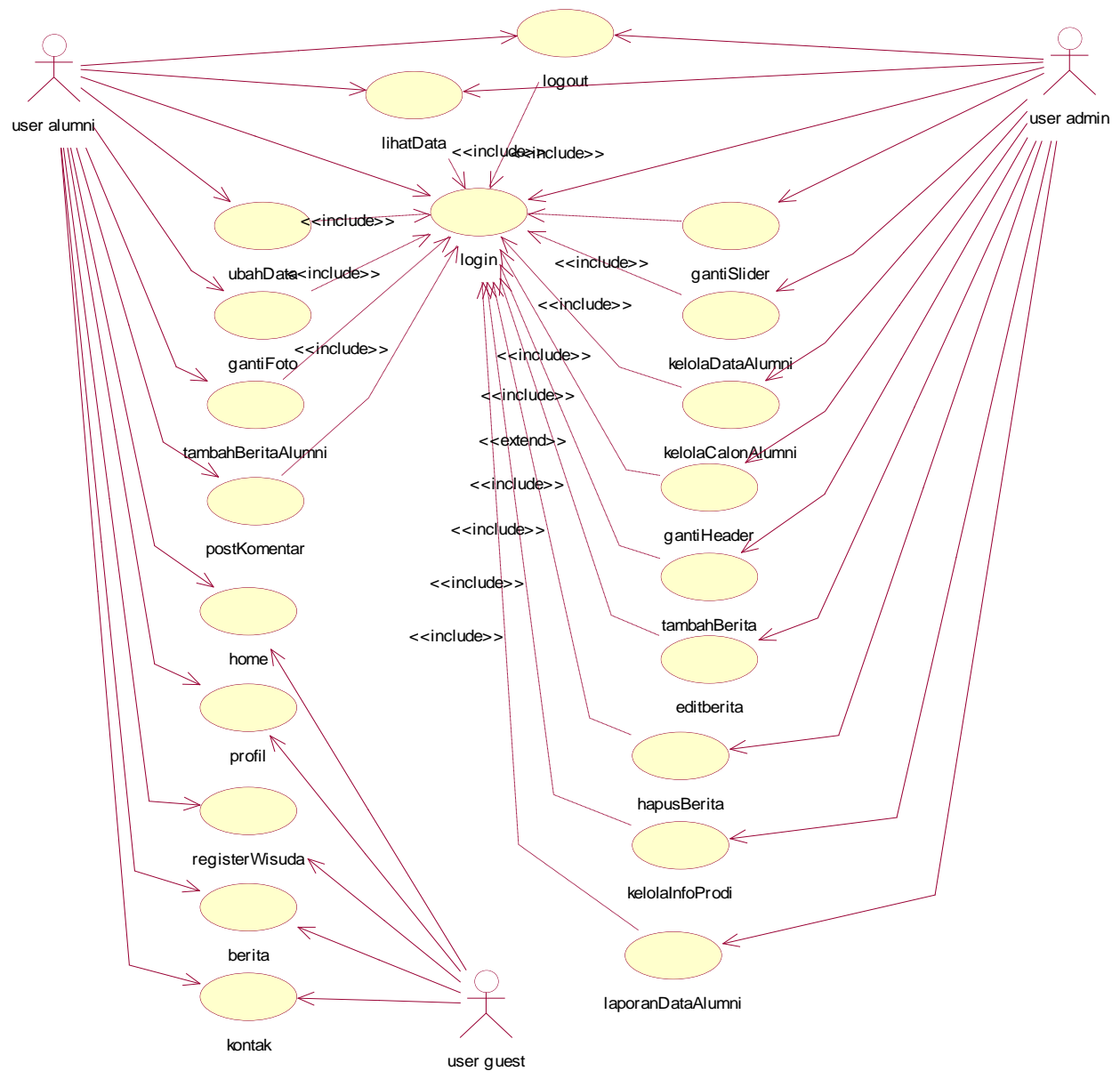

Gambar 2. Use Case Diagram 


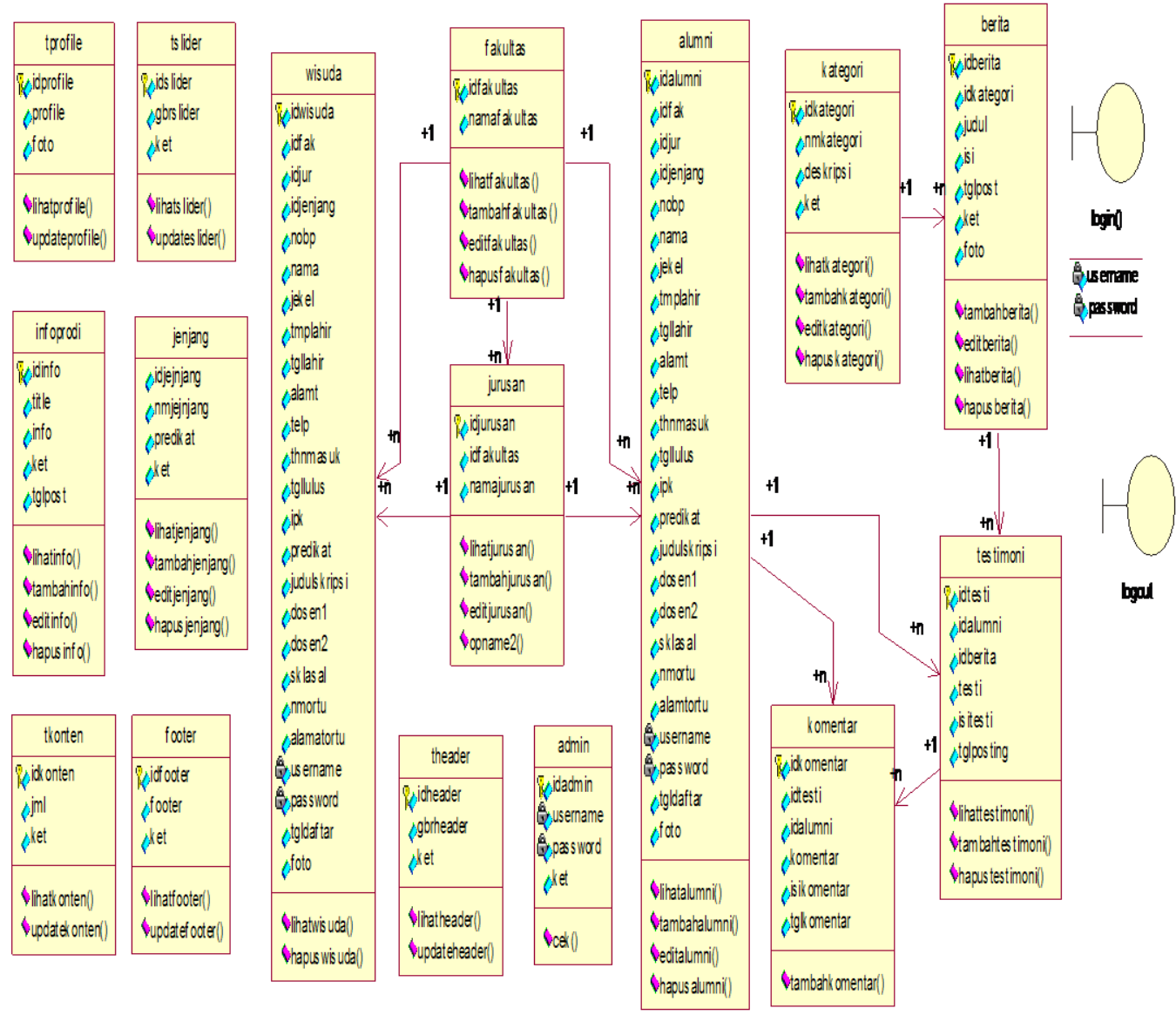

Gambar 3. Class Diagram

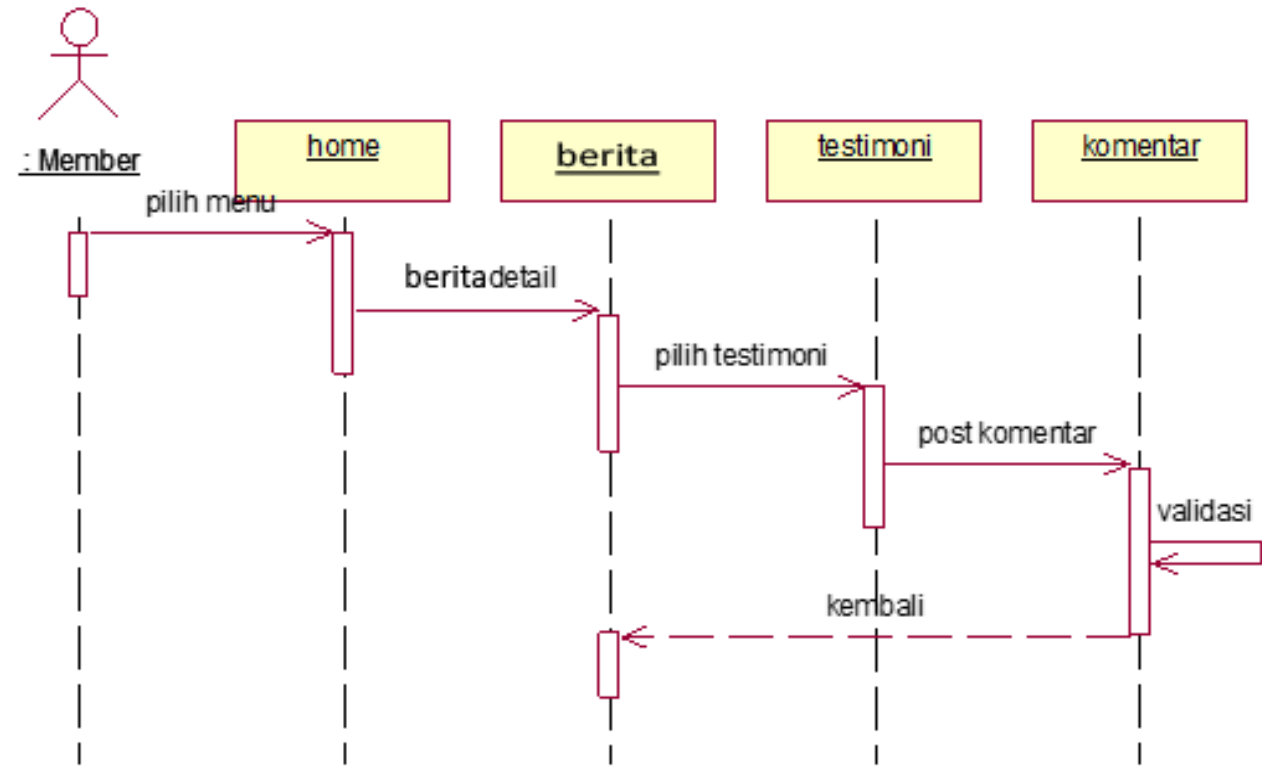

Gambar 4. Sequence Diagram 
UNES Journal Of Scientech Research

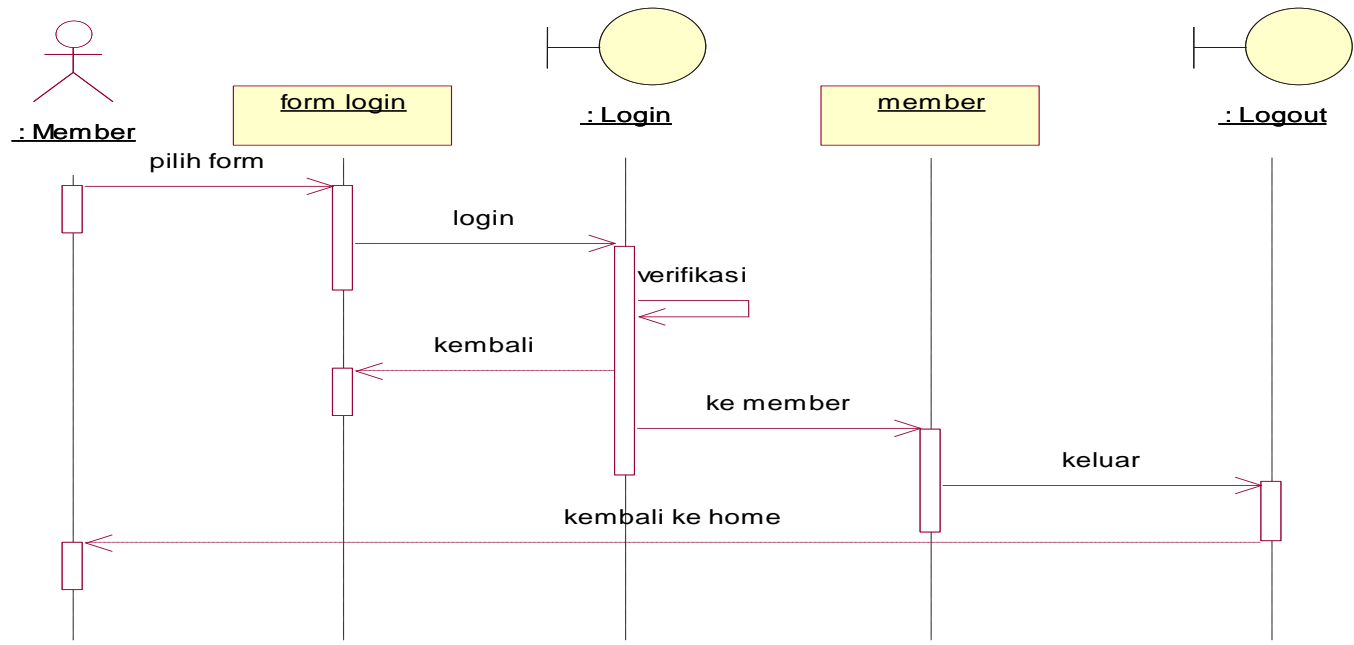

Gambar 5. Sequence Diagram

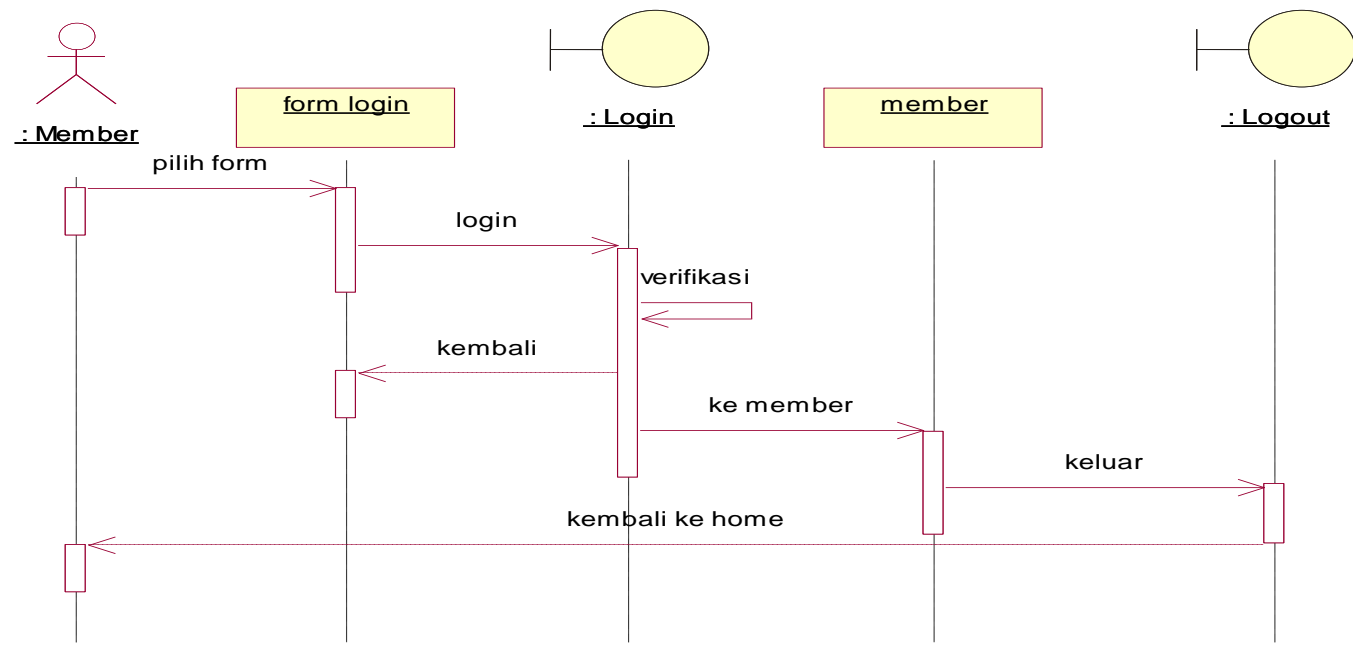

Gambar 6. Sequence Diagram

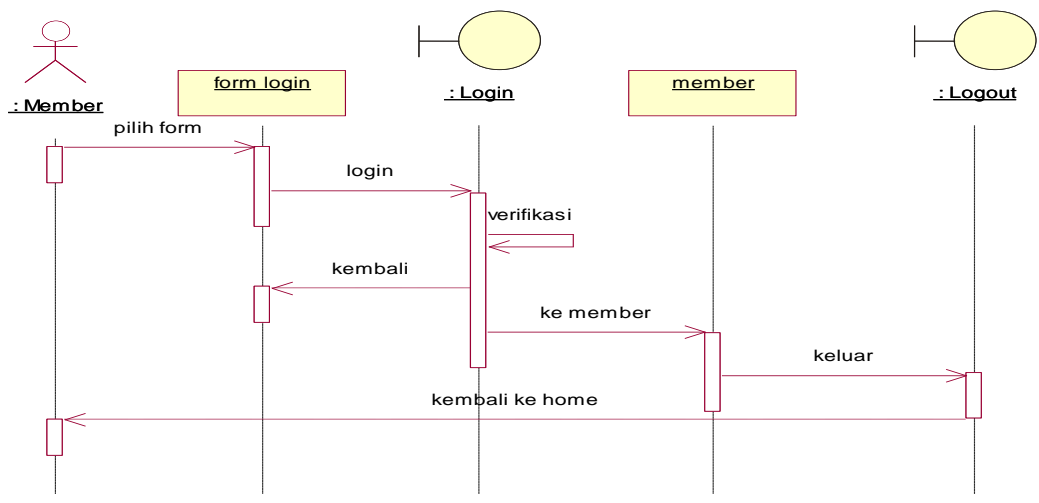

Gambar 7. Sequence Diagram 


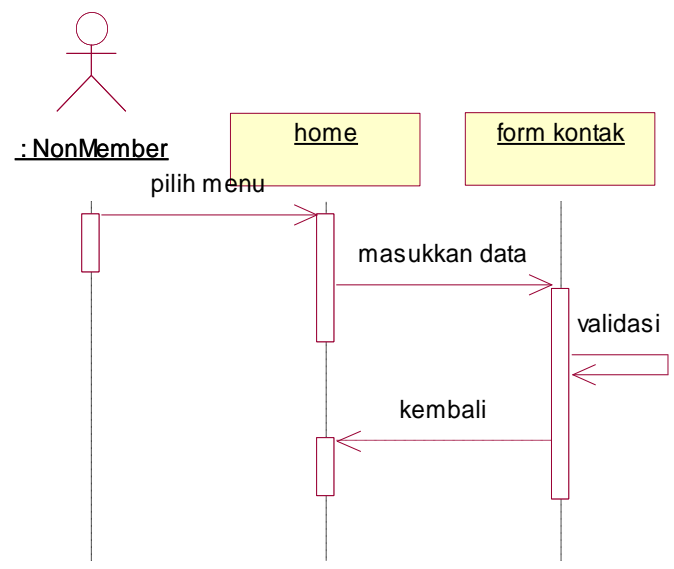

Gambar 8. Sequence Diagram

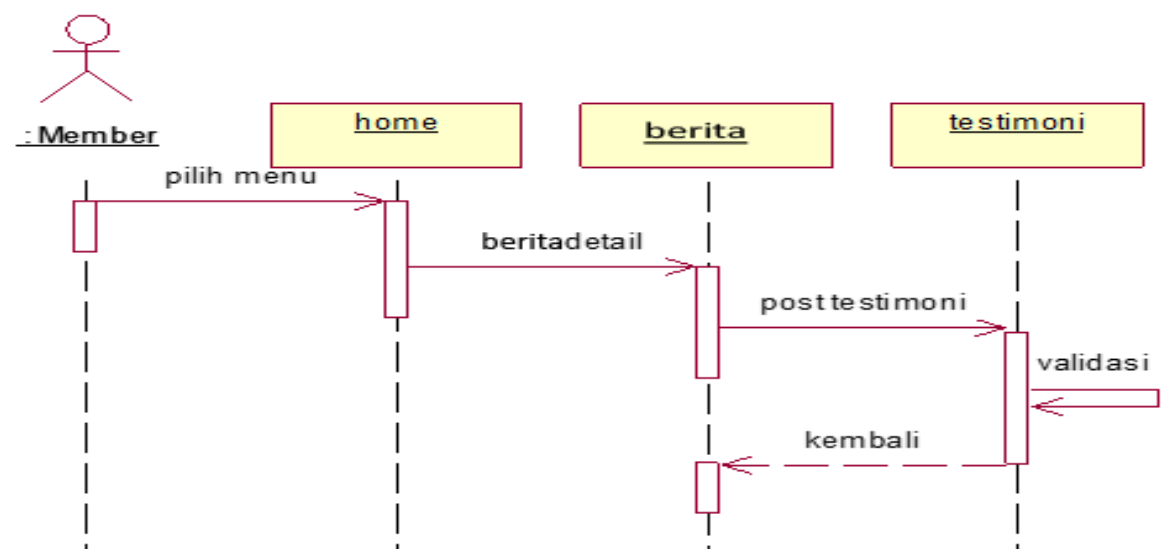

Gambar 9. Sequence Diagram

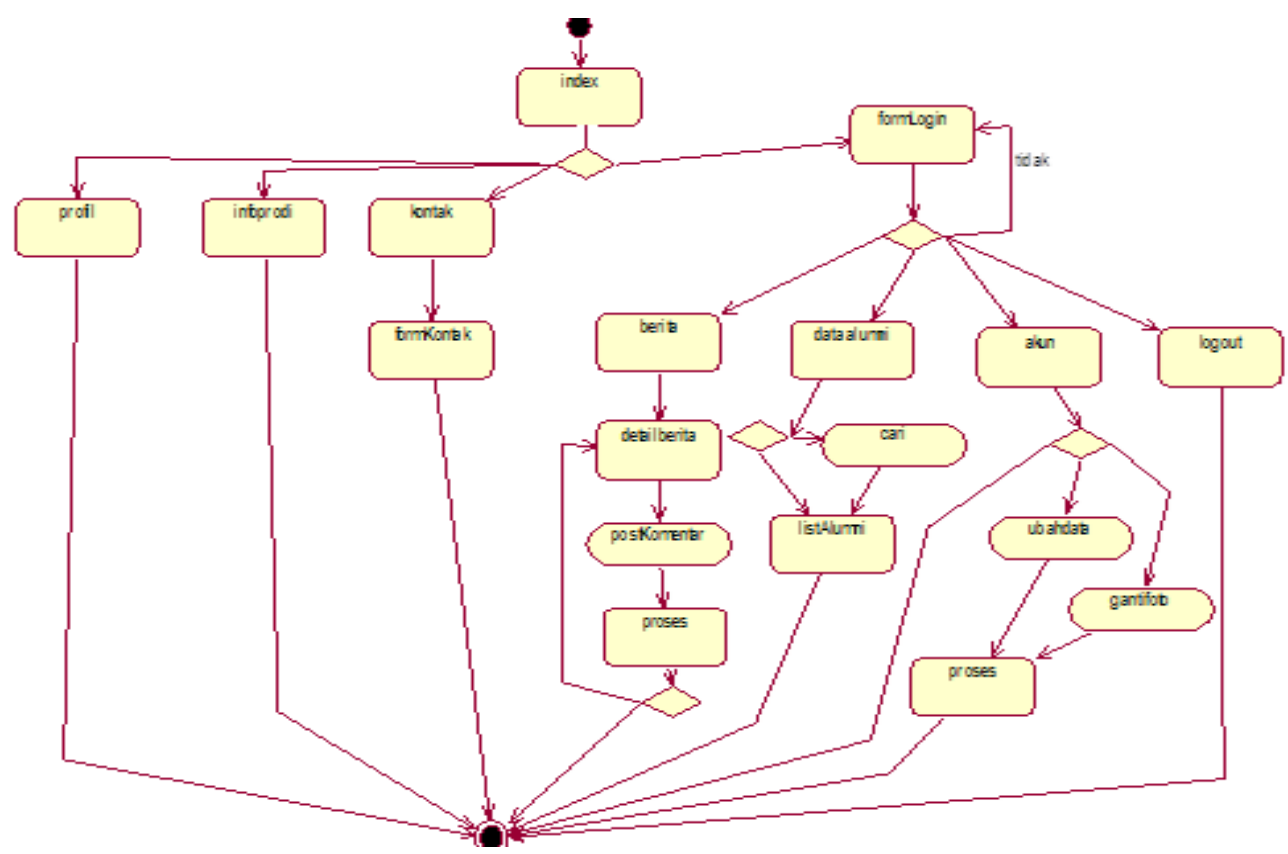

Gambar 10. Activity Diagram 


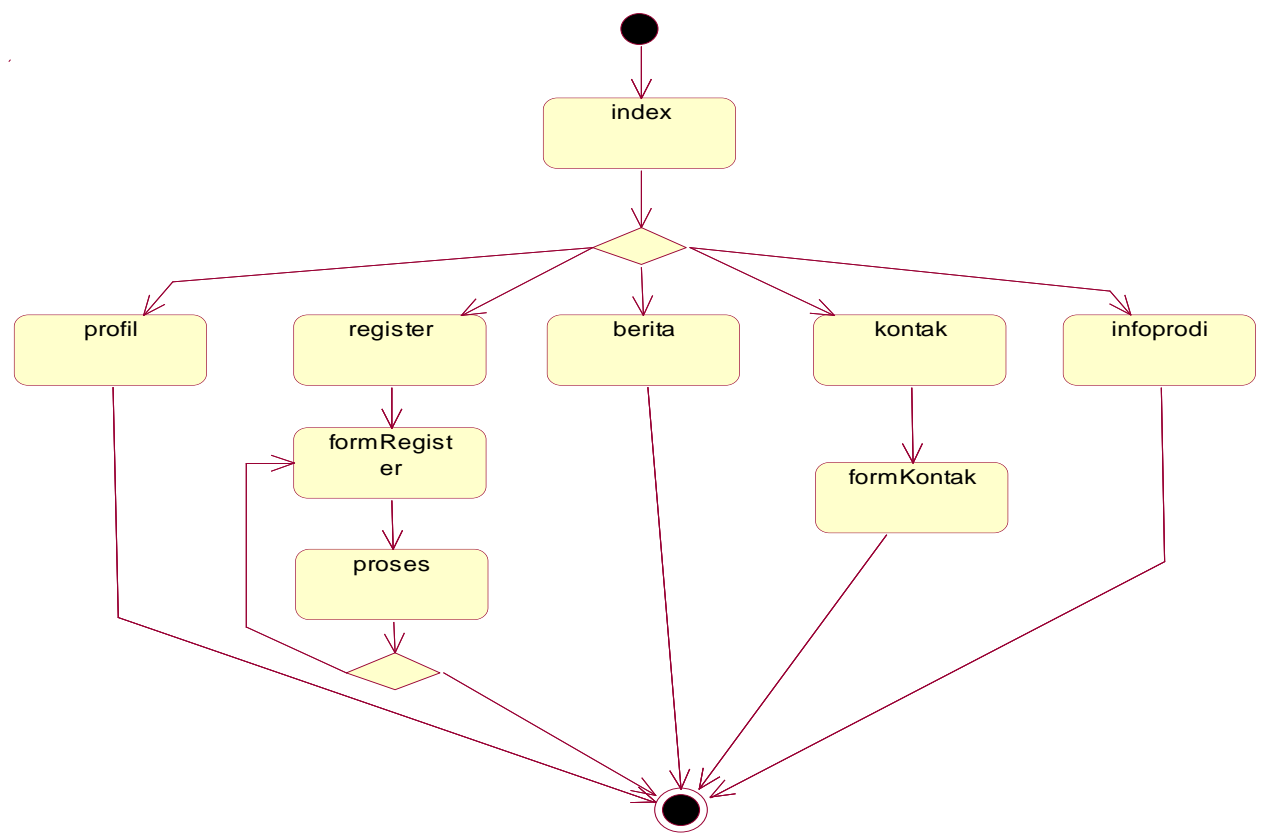

Gambar 11. Activity Diagram

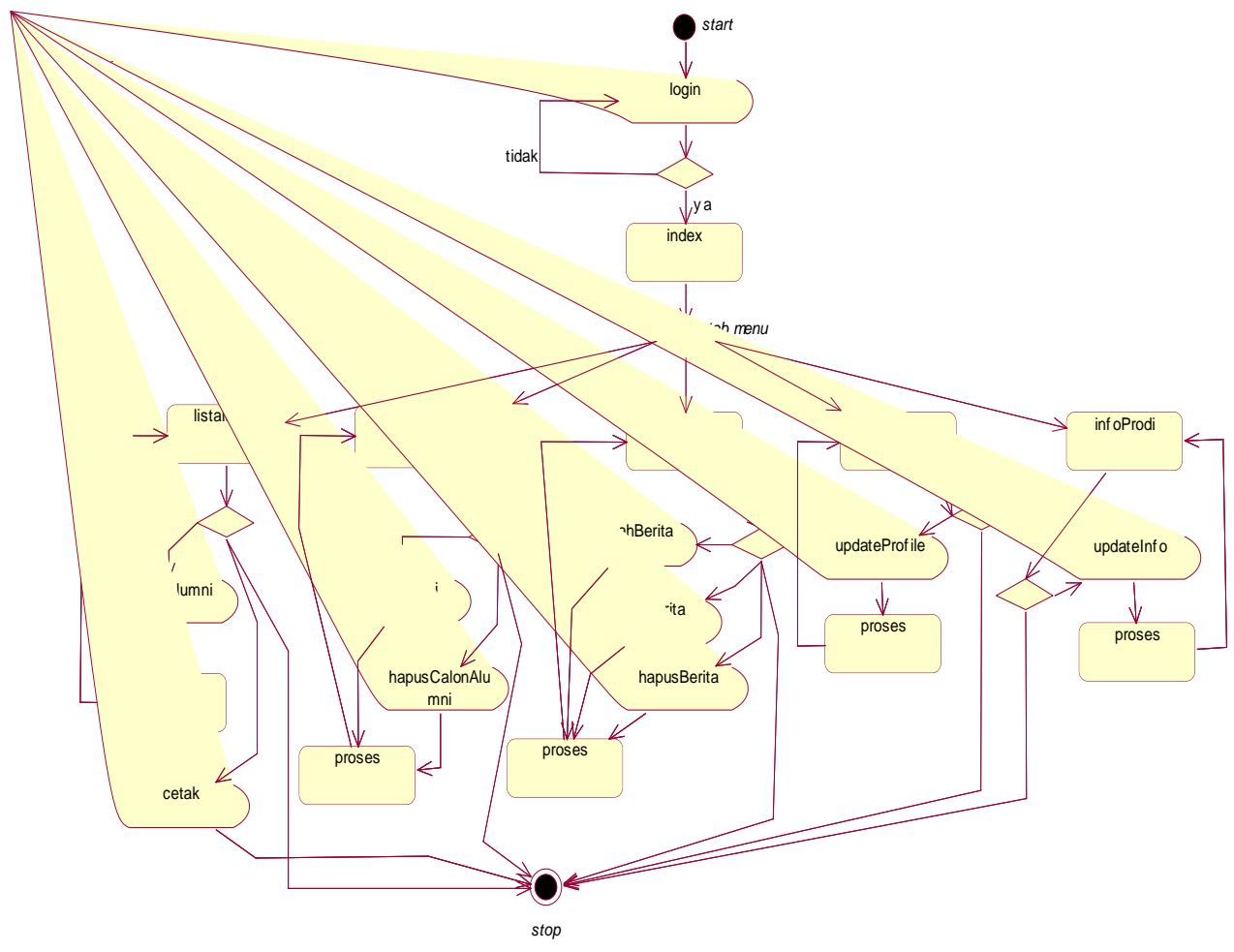

Gambar 12. Activity Diagram 


\begin{tabular}{|l|c|}
\hline \multicolumn{1}{|c|}{ ClientBrowser } \\
Google Crome \\
Mozila Firefox \\
Internet Explorer
\end{tabular}

Gambar 13. Deploymant Diagram

\section{Pengembangan Prototype}

Pada pengembangan prototype disini dapat ditampilkan desain dari database serta tampilan dari sistem yang dirancang seperti yang terlihat dibawah ini :

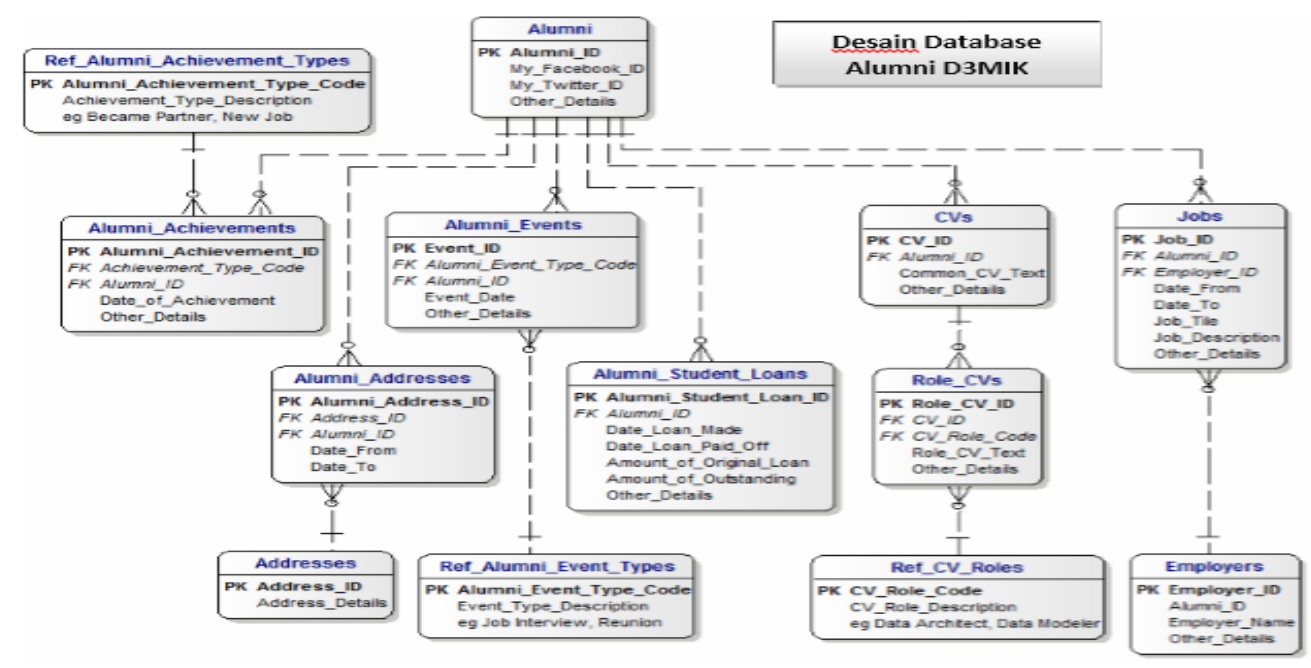

Gambar 14. Rancangan Database 


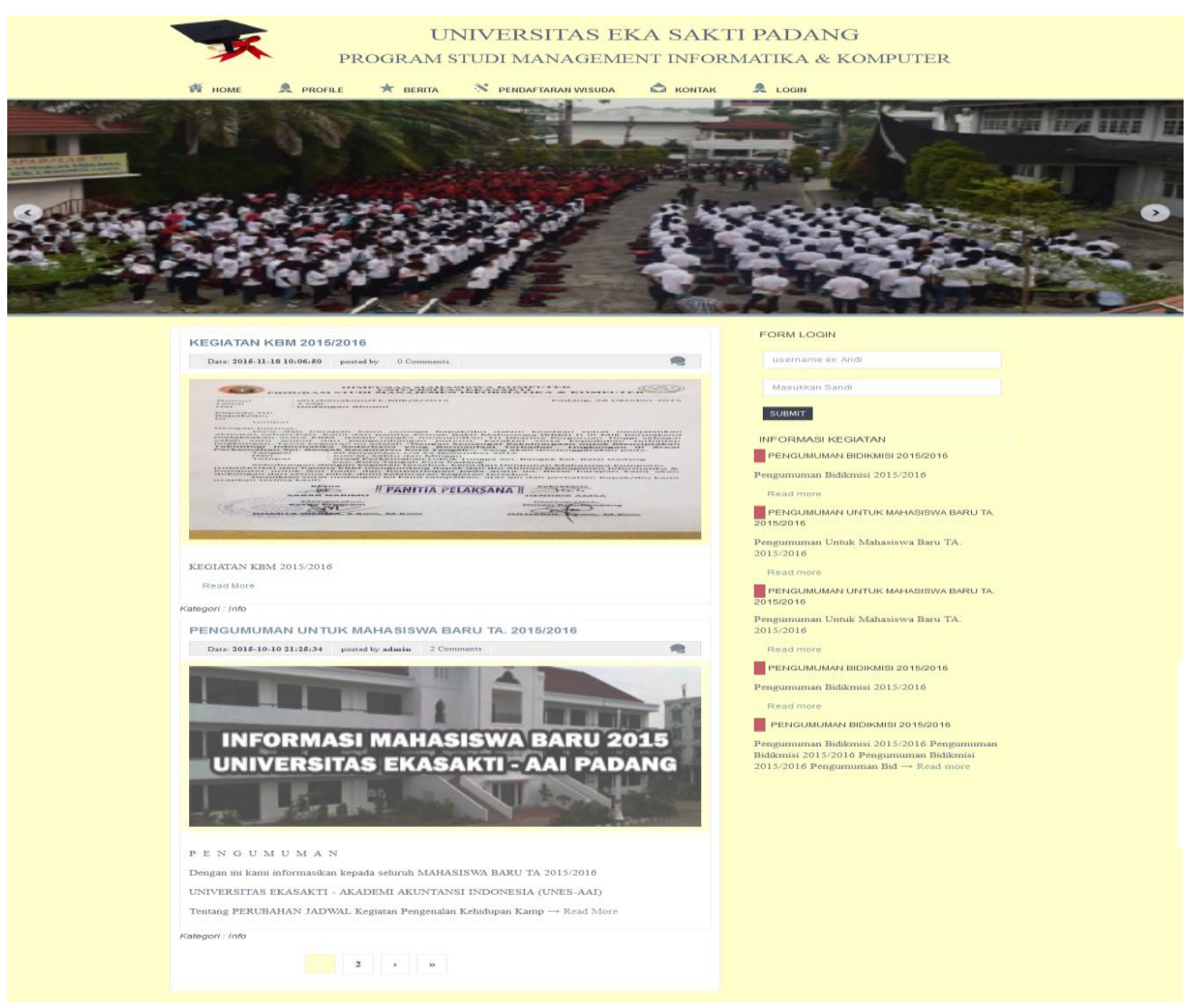

Gambar 15. Prototype Website Alumni

\section{KESIMPULAN}

Dari berbagai penjelasan yang telah diuraikan dalam penelitian ini, maka dapat disimpulkan beberapa hal sebagai berikut :

1. Aplikasi ini dapat merekam data terkait data alumni yang menghasilkan sistem informasi berbasis web bagi alumni, mahasiswa, dan Program Diploma III Manajemen Informatika dan Komputer Universitas Ekasakti Padang sesuai kebutuhan

2. Aplikasi ini merekam data dengan menggunakan basis data sehingga data alumni tersimpan secara terstruktur dengan memiliki id pada masing - masing alumni

3. Dengan dibuatnya website alumni ini maka user dapat langsung mencari data alumni dan menyampaikan informasi sehingga informasi mudah tersampaikan kepada alumni dan yang membutuhkan informasi terkait alumni, karena dapat diakses menggunakan internet. 


\section{REKOMENDASI}

Sistem ini nantinya mampu didalam mengakomodasi data alumni disetiap perguruan tinggi selain itu sistem ini juga dapat menjadi pusat informasi bagi para pencari kerja khususnya para alumni.

\section{DAFTAR PUSTAKA}

Richard F.Neuschel 2005. Managemen of System, Mc Graw-Hill, Universitas: Michigan Jogiyanto. 2005, Analisis dan Desain Sistem Informasi Pendekatan Terstruktur, ANDI : Yogyakarta

George M.Scott. 2003. Principles of Managemen Information System, Mc Graw-Hill, Universitas Michigan.

A.S, Rosa , M.Shalahudin, 2013, Rekayasa Perangkat Lunak Terstuktur dan Beroriontasi Objek. Informatika : Bandung

Flawer, Martin, 2007, Uml Distiled. Andi : Yokyakarta.

Kharisma U.K 2012. Jurnal Sistim Informasi Alumni Program Studi Sistim Informasi Universitas Widyatama Berbasis Web. Tugas Akhir Fakultas Teknik Program Studi Sistem Informasi : Bandung.

Ainul Yaqin M., A'la, S., Faiz A.R., Annisa, P.K., 2010, Pengembangan sistem informasi alumni berbasis web fakultas sains dan teknologi universitas islam negeri maulana malik ibrahim malang, Jurnal Matics, UIN Malang, 4(1 ): 2010.

Bahtiar,N.,Binarso., Sarwoko. (2012). Pembangunan Sistem Informasi Alumni Berbasis Web Pada Program Studi Teknik Informatika Universitas Diponegoro. Semarang : Universitas Diponegoro. 